Research Square
Preprints are preliminary reports that have not undergone peer review.

They should not be considered conclusive, used to inform clinical practice, or referenced by the media as validated information.

\title{
Obesity Knowledge, Perception and Dietary Behaviour among Nigerian Undergraduate Population
}

Monday Olodu ( $\square$ mondayolodu@gmail.com )

Obafemi Awolowo University https://orcid.org/0000-0002-1928-9209

Ismail Olaide Muslim

Obafemi Awolowo University

Ololajulo Ojogbon

Obafemi Awolowo University

\section{Research article}

Keywords: Obesity knowledge, Perception, Dietary behaviour

Posted Date: January 23rd, 2020

DOI: https://doi.org/10.21203/rs.2.21699/v1

License: () (i) This work is licensed under a Creative Commons Attribution 4.0 International License. Read Full License 


\section{Abstract}

Background: A steadily increasing trend of obesity among young adults is becoming evident, and this could lead to an increased burden of chronic noncommunicable diseases in adulthood. This study assessed the knowledge of undergraduates on obesity and its related conditions, their perception and dietary behaviour.

Method: A total of 394 undergraduates of Obafemi Awolowo University were recruited using a multistage sampling technique. A self-administered questionnaire which had four sections was used to collect data. Knowledge of obesity, perception and dietary behaviour was assessed with carefully chosen questions. Scores were computed with +1 for a correct response and 0 for an incorrect response. These scores were graded as good/positive or poor/negative using the mean or median score as the cut-offs. Chi-square test was done to assess the relationship between categorical variables. The statistical significance level was set at $p<0.05$.

Results: Majority (64.0\%) had poor knowledge of obesity and were mostly males (54.0\%), and $58.4 \%$ had a positive perception of obesity and were mostly females (62.1\%). Also, $57.6 \%$ had poor dietary behaviour and were mostly males (58.8\%). A statistically significant relationship (X2=10.546; $p=0.001)$ was found between obesity knowledge and perception. There was no statistically significant relationship between obesity knowledge and dietary behaviour.

Conclusion: Most of the undergraduates had poor knowledge of obesity and poor dietary behaviour. Therefore, the creation of healthy eating awareness and integration of nutrition education into all fields of study is vital to stemming the tide of the future obesity epidemic in our campus.

\section{Background}

Obesity is a condition of abnormal accumulation of fat in the adipose tissue, to the extent that health may be impaired. ${ }^{[1,2]}$ It is measured with body mass index greater than or equals to $30 \mathrm{~kg} / \mathrm{m}^{2}$. Obesity and Overweight are the fifth leading risk for global deaths. ${ }^{[1,3]}$ More than 1.9 billion adults are overweight and 600 million are obese ${ }^{[4]}$ The potential medical consequences of obesity have been documented extensively, particularly in relation but not limited to its co-morbidities such as cardiovascular diseases, type II diabetes mellitus, dyslipidemia, certain types of cancers, especially the hormonally related (breast, ovarian, endometrial, and prostate) liver and large-bowel cancers and gallbladder disease. The non-fatal, but debilitating health problems associated with obesity also include respiratory difficulties, chronic musculoskeletal problems, skin problems and infertility. ${ }^{[4]}$ Although, obesity and overweight were once considered problems of high-income countries, a rapid increase in obesity rates have also been documented in the developing world. ${ }^{[5]}$ Until recently, the report shows that a steadily increasing trend of obesity among young adults is becoming evident. ${ }^{[6,7]}$

The factors associated with obesity include age, gender, ethnicity, culture, food habits, lifestyle factors, and lack of physical activity. ${ }^{[8,9]}$ The increased supply of processed food, rapid urbanization and changing lifestyles has led to a shift in dietary patterns leading to the global burden of obesity. ${ }^{[6]}$ Studies also revealed that university students failed to meet the recommended intakes of fruits and vegetables ${ }^{[10,11]}$, frequently engage in snacking habits ${ }^{[12]}$ and had a higher frequency of fast food consumption. ${ }^{[13]}$ These are dietary behaviour that can lead to unintended weight gain. Adequate knowledge and awareness of the consequences of obesity through public enlightenment programme has been reported to be capable of lessening the prevalence of chronic noncommunicable diseases (NCDs). Although there were many studies targeting the undergraduates' pattern of nutrition, their knowledge and perception of obesity as the major risk factor for NCDs have not been fully explored. ${ }^{[2]}$ Therefore, it is of utmost importance to assess how much undergraduates know about obesity and its related conditions, their perception of it and the influence of their knowledge on their dietary behaviour, if any.

\section{Methods}

\section{Study settings}

This descriptive cross-sectional survey was conducted at Obafemi Awolowo University, lle-lfe, Nigeria from April 2017 to June 2017 . It is a federal government owned and operated Nigerian university situated on a vast expanse of land totaling 11,681 hectares in lle-lfe, Osun State, Southwest, Nigeria. The university was founded in 1961, and offers undergraduate and postgraduate degree programmes in multiple fields of study ranging from humanities, the arts, natural sciences, engineering, technology and medical sciences, with a student population of about thirty-five thousand. The University comprises of central campus, the student residential area, the staff quarters and a Teaching and Research Farm. The campus is built on about 5,000 acres $\left(20 \mathrm{~km}^{2}\right)$ and comprises of academic, administrative units and service centres. The student residential area is made up of 10 undergraduate hostels and a postgraduate hall of residence The academic area is not too far from the residential area. Many restaurants and fast food joints are located both in the academic area, as well as, in the residential area. Selected undergraduates of Obafemi Awolowo University in the chosen departments and who are willing, participated in the study.

\section{Sampling}

The sample size was calculated using Leslie Fischer's formula for a single population proportion $\left[n=Z^{2} p(1-p) / d^{2}\right]$. The prevalence of university students with good knowledge of obesity was $49.8 \%$ from a previous study ${ }^{[14]}$, with a $95 \% \mathrm{Cl}$ and precision of $5 \%$. After accounting for a non-response rate of $10 \%$, the total sample size was rounded up to 423. Multi-stage sampling technique was used in selecting participants. In the first stage, the College of Health Sciences, Faculty of Pharmacy, and Faculty of Agriculture were excluded based on the assumption that they might have been exposed to relevant teachings on obesity. Out of the remaining eight faculties that met the inclusion criteria, five faculties were selected using the simple random technique (balloting method). These were faculties of Law, Administration, Education, Social sciences and Arts. In the second stage, three departments were selected in each of the five faculties by simple random technique (balloting method) with the exception of faculty of Law which has only one department. The third stage involves proportionate 
allocation of the sample based on the estimated number of students available in each department and the selection of participants by simple random sampling technique (balloting method).

\section{Data collection}

A structured self-administered questionnaire which had four sections was used to collect data from the respondents. The questionnaire contained 11 questions to assess the respondent's knowledge of obesity, 16 questions to assess the perception of obesity and food frequency questionnaire to assess the dietary behaviour of participants. The questions on obesity knowledge and perception were adapted from previously published research work. ${ }^{[15-17]}$ The questionnaire was pretested among 40 undergraduates in other faculties not included in the study to check for ambiguity, and all the necessary corrections were effected.

\section{Variables and measures}

Obesity knowledge questions assessed the respondent's awareness, sources of information, basic knowledge and assessment method of obesity. The 11 questions were scored 1 for correct response and incorrect response 0 with the score range between 0-20 points. A score greater than or equals to the mean (10 points) was graded good knowledge and vice versa. The perception questions were measured with a 4-point Likert scale. For every positive question, strongly agree (SA) carries the highest mark and a reverse score for every negative question. The total obtainable score ranged between 16-64 points. A score below the median score was classified as negative and above as positive. Food frequency questionnaire was used to assess the dietary intake of 7 food groups (fruit, vegetable, fried foods, sweets, fatty snacks, soft drinks, barbecue/ Suya) that are common in the study location and are likely to lead to excessive weight gain if consumed too often. The frequencies of consumption of these foods per week (once/week, 1-2 times/week, 3-4 times/week, 5-6 times/week and every day) were constructed based on previous studies. ${ }^{[18,19]}$ Intake of healthy foods, including fruit and vegetables, was dichotomized to less than 5 times/week (unacceptable) and more than 5 times/week (acceptable). While intake of unhealthy food, including sugary drinks, fatty snacks, fried foods and barbecue were dichotomized to 2 times/week or less (acceptable) and more than 2 times/week (unacceptable). ${ }^{[20]}$ The total obtainable score ranged between 0-7 points. A score below the median score (4 points) was classified as poor dietary behaviour and vice versa.

\section{Data analysis}

Statistical analysis was done by means of SPSS version 20. At Univariate level, descriptive statistics was done to analyze descriptive data and the results are presented as frequencies and percentages for categorical variables and as means and standard deviations for continuous variables. Knowledge, perception and dietary behaviour scores were computed with +1 for a correct response and 0 for an incorrect response. These scores were graded as good or poor knowledge, positive and negative perception, good and poor dietary behaviour using the mean and median scores as the cut-offs. Bivariate chi-square test was done to assess the relationships between knowledge of obesity, perception and dietary behaviour. The statistical significance level was set at $p<0.05$. Ethical clearance was obtained from the Research and Ethical Committee of the Institute of Public Health, Obafemi Awolowo University, Ile-Ife. Written informed consent was obtained from the participants. Confidentiality was maintained by using serial numbers instead of names and keeping the data in a pass-worded computer.

\section{Results}

Table 1 shows the Socio-demographic characteristics of the study participants. Out of 423 questionnaires that were administered, 394 were accurately filled and subjected to analysis after sorting and cleaning. This gave a response rate of $93.1 \%$. The mean age of the respondents was $20.25 \pm 2.7$ years and were mostly females (53.0\%). Majority of the respondents were single (96.7\%), were of Yoruba tribe (88.1\%) and were Christians (85.8\%). Most of the participants do not have more than 4 siblings (72.1\%) and maintained the first 3 positions (73.6\%) among siblings. Respondents' parents were learned (father $70.8 \%$, mother $62.7 \%$ ) and were mostly self-employed (father $47.5 \%$, mother $52.5 \%$ ). Majority of the students received 20,000 naira and below as monthly stipends and were mostly 200 level (49.7\%) students.

\section{Table 1: Socio-demographic Characteristics of Respondents}

Table 2 shows the respondents' knowledge of obesity. Among 394 respondents interviewed, 373 (94.7\%) have heard about obesity. The two common sources of information were media (55.0\%) and books (42.1\%). Majority of the respondents do not know that the cause of obesity is multi-factorial (71.8\%), is associated with serious health conditions (92.5\%) and can affect both sexes (50.5\%). In terms of obesity assessment, only $34.3 \%$ have heard about body mass index (BMI). Among those who have heard of BMI, $84.4 \%$ knew what it stands for, $40.6 \%$ knew the healthy range and majority $(75.8 \%)$ have not checked their BMI in the last three months. The aggregate score showed that majority $(64.0 \%)$ of the respondents have poor knowledge of obesity and were mostly males (54.0\%). 
Table 3 shows the respondents' perception of obesity. Out of 373 respondents that have heard about obesity, majority agreed that it can be addressed medically (85.5\%) and should not be viewed as a sign of good living (90.1\%). Majority also agreed that dietary modification (87.1\%), reduction in salt intake $(84.0 \%)$ and being physically active ( $82.6 \%)$ can help to prevent obesity. However, some disagreed with the statements that obesity is a disease (27.3\%) and can lead to stigmatization (28.1\%). About $24 \%$ also agreed that obesity makes one looks mature. The aggregate score showed that majority (58.4\%) of the respondents have a positive perception of obesity and were mostly females (62.1\%) (Table III).

\section{Table 3: Perception of obesity by the respondents}

Table 4 shows the dietary behaviour of the respondents. The proportion of students who consumed fruits every day was $8.0 \%$ and less than $5 \%$ consumed vegetable every day. These foods were mostly consumed by females. The proportion of respondents who consumed fried foods (51.2\%), snacks (52.5\%) and candies (52.5\%) every day were higher in females. The proportion of respondents who consumed sugary drinks every day were higher in males (61.5\%). The aggregate score showed that majority (57.6\%) of the respondents have poor dietary behaviour and were mostly the males (58.8\%).

\section{Table 4: Dietary behaviour of the respondents}

Table 5 showed that there was a statistically significant relationship between obesity knowledge and perception of obesity by the respondents. A higher proportion of students with good knowledge also had a positive perception of obesity $\left(X^{2}=10.546 ; p=0.001\right)$. There is no statistically significant relationship between obesity knowledge and dietary behaviour of respondents $\left(X^{2}=0.690 ; p=0.450\right)$. However, a higher proportion of respondents with poor dietary behaviour also had poor knowledge.

Table 5: Relationship between obesity knowledge, perception and dietary behaviour of respondents

\section{Discussion}

Studies have shown that obesity is increasing among young adults ${ }^{[6,7,21,22]}$ and the link with chronic non-communicable diseases is significant. ${ }^{[23,24]}$ This present study showed that the knowledge of obesity and its related factors remained poor among university students, especially non-science disciplines. This poor knowledge influenced their perception as half $(49.7 \%)$ of the participants have a negative view of obesity and its related factors. This relationship is statistically significant $(p<0.05)$. Also, the poor knowledge of obesity and its related factors might have contributed to the poor dietary behaviour showed by the majority $(56.7 \%)$ of the respondents.

In the present study, when respondents were asked about their awareness of obesity, 373 (94.7\%) claimed to have heard about it. The proportion of females reported to have heard about obesity in this study was higher and this is similar to a study in Kenya. ${ }^{[15]}$ The reason for this could be that females generally are more conscious of their body image. ${ }^{[25,26]}$ When asked about their source of information, most $(55 \%)$ of the respondents acknowledged that social media was their major source of obesity information. This contrasted the findings of Thielemann ${ }^{[27]}$ in the United States where most participants got their information from the school. While social media could serve as a major source of information, the recency and credibility of information obtained must be critically evaluated. ${ }^{[28,29]}$ It is shocking to know that majority of the respondents do not know that obesity is associated with serious health conditions, multi-factorial and can affect both sexes. On obesity measurements, only $34.3 \%$ have heard about body mass index (BMI), less than half (40.6\%) knows the healthy range and only $24.2 \%$ have checked their BMI in the last 3 months. Ramasamy et al ${ }^{[15]}$ also reported similar results in Kenya. On the aggregate, majority (64\%) of the respondents have poor knowledge of obesity. This was similar to the results reported among students at Ohio by Emily et al. ${ }^{[30]}$ However, Deotale ${ }^{[16]}$ reported $100 \%$ good knowledge of obesity among medical students in India. This is not surprising as medical students are exposed to lectures on obesity and its associated factors.

On obesity perception, some still viewed obesity as evidence of good living (10\%), a measure of socioeconomic status (17.2\%), a sign of maturity (23.3\%), makes clothes fit better (11.5\%) and as a way of earning respect (13.2\%). These negative perceptions have been well reported on by previous researchers among adults. ${ }^{[15,17]}$ Cumulatively, more of the respondents in this study have a positive perception of obesity. However, a good number still nurture a distorted view of obesity despite being in an academic environment. Pro-active measures, therefore, need to be taken to correct these views by creating awareness on obesity and its associated health risk. Improving the knowledge of the students by way of education would help to prevent the rise in obesity and it's attendant's health consequences among adults in the future. ${ }^{[31,32]}$

World Health Organization (WHO) experts recommended the intake of a minimum of $400 \mathrm{~g}$ of fruits and vegetables daily for the prevention of chronic noncommunicable disease. ${ }^{[33]}$ This study shows that $8.0 \%$ and $4.1 \%$ consumed fruits and vegetables respectively on a daily basis. This low prevalence of fruit

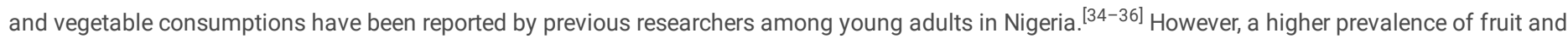
vegetable consumptions have been well reported on among young adults in developed countries. ${ }^{[19,37]}$ This does not come as a surprise as report already showed that for the past two decades, there has been a rapid and marked socioeconomic advancement in developed countries leading to a significant 
improvement in the lifestyles and dietary pattern of young adults. ${ }^{[19,38]}$ In this study, more females tend to consume more fruits daily than males. This is in contrast to a higher proportion of males reported by Anwar. ${ }^{[19]}$ Also, more females consumed fried foods daily. Similar results were reported by another researcher. ${ }^{[19]}$ The proportion of respondents that consumed unhealthy snacks in this study is low compared to $32 \%$ reported by Poobolan et al. ${ }^{[37]}$ The prevalence of poor dietary behaviour in this study was higher, and this must have been largely influenced by the poor knowledge of obesity reported in this study. There was a significant relationship between knowledge of obesity and perception. This shows that good knowledge of obesity can positively influence people's perception of it and subsequently help to guide their food choices. This study provides insight into the future state of health of the young adults who are in their transition phase of becoming mature adults. Nutrition intervention at this phase will help to prevent future obesity challenges which would reduce

quality of life in adulthood. ${ }^{[39]}$ One major limitation of this study was the use of a sample of students from Obafemi Awolowo University, lle-lfe, Nigeria which may affect generalizability of results. Also, there is a likelihood of recall bias as responses were self- reported.

\section{Conclusion}

Knowledge of obesity and its related conditions among undergraduates is poor. This poor knowledge contributed to the negative perception and poor dietary behaviour among respondents. Therefore, the creation of healthy eating awareness and integration of nutrition education into all fields of study is vital to stemming the tide of the future obesity epidemic.

\section{Abbreviations}

BMI: Body mass index; Cl: Confidence interval; NCDS: Non-communicable diseases; SA: Strongly agree; SPSS: Statistical product and service solutions; WHO: World Health Organisation

\section{Declarations}

\section{Acknowledgement}

We thank the four research assistants who assisted in data collection and sorting during the field as well as all the participants who took part in the study.

\section{Authors' Contribution:}

OMD makes substantial contributions to the conception and design of the study while $\mathrm{MIO}$ and $\mathrm{OO}$ make vital contributions in the implementation. All authors were involved in data collection, analysis and interpretation. All authors read and approved the final manuscript.

\section{Funding}

This research did not receive any specific funds from any agencies. It was self-funded by the authors.

\section{Availability of data and material}

The datasets used during the current study are available from the corresponding author on reasonable request.

\section{Ethics approval and consent to participate}

Ethical clearance was obtained from the Institute of Public Health Research and Ethics Committee, Obafemi Awolowo University, Ile-Ife, Nigeria. Written consent was obtained from individual participants before filling the questionnaire.

\section{Consent for publication}

Not applicable

\section{Competing interests}

The authors declared that they have no competing of interests.

\section{References}


1. World Health Organisation. Obesity: preventing and managing the global epidemic. 2000.

2. Olusanya J.O 00. Prevalence of obesity among undergraduate students of Tai Solarin University of Education, ljagun, ljebu-Ode. Pak J Nutr 2011;(10).

3. World Health Organization (WHO). Global health risks: Mortality and burden of disease attributable to selected major risks. 2009.

4. World Health Organization (WHO). Obesity and overweight. 2016.

5. Popkin B.M, Adair L.S. NS. Global nutrition transition and the pandemic of obesity in developing countries. Nutr Rev 2012;70:3-21.

6. Fanzo J, Hawkes C, Udomkesmalee E, Afshin A, Allemandi L, Assery O, Baker P, Battersby J, Bhutta Z, Chen K CC. Global Nutrition Report: Shining a light to spur action on nutrition [Internet]. 2018. Available from: http://ebrary.ifpri.org/cdm/ref/collection/p15738coll2/id/128484

7. Anderson DA, Shapiro JR, Lundgren JD. The freshman year of college as a critical period for weight gain: An initial evaluation. Eat Behav 2003;4(4):3637.

8. Nojomi M NS. Obesity among university students, Tehran, Iran. Asia Pac J Clin Nutr 2006;15.(4):516-20.

9. Tahareh Mokhtari RJ and HAS. Lifestyles \& Psychological factors.pdf. Pakistan J Nutr 2015;14(1):18-28.

10. Moy FM, Johari S, Ismail Y, Mahad R, Tie FH WIW. Breakfast Skipping and It's Associated Factors among Undergraduates in a Public University in Kuala Lumpur. Mal J Nutr 2009;15(2):165-74.

11. Huang T. T., Harris K. J., Lee R. E., Nazir N., Born W. KH. Assessing overweight, obesity, diet and physical activity in college students. J Am Coll Heal 2003; (52):83-6.

12. Yahia N., Achkar A., Abdallah A. RS. Eating habits and obesity among Lebanese University students. Nutr J 2008;(7):32-6.

13. K, Alizadeh M G. Health related life style among the Iranian medical students. Res Biol Sci 2008;3(1):4-9.

14. Awotidebe TO. An Assessment of Knowledge of Nigerian Female Undergraduates on Obesity as a Risk Factor for Cardiovascular Disease in Women. Am J Heal Res 2014;2(5):50.

15. Ramasamy P, David N, Zipporah W, Kiplagat V. A study to assess knowledge and perception on obesity among female aged eighteen years and above living in ladies dorm at UEAB, Kenya. Int J Res Med Sci 2018;6(5):1496.

16. Deotale MK, Ranganathan U, Akarte S V. Prevalence of overweight and obesity among medical students and their knowledge, attitude and practices about obesity. Int J Sci Reports 2015;1(1):74-9.

17. Ojofeitimi E.O., Adeyeye A.O., Fadiora A.O., Kuteyi A.O., Faborode T.G., Adegbenro C.A, Bakare O.E., Setiloane K. TKS. Awareness of obesity and its health hazard among women in a university community. Pak JNutr 2007;6(5):502-5.

18. Sedibe MH, Pisa PT, Feeley AB, Pedro TM, Kahn K, Norris SA. Dietary habits and eating practices and their association with overweight and obesity in rural and urban black South African adolescents. Nutrients 2018;10(2):1-18.

19. Anwar M, Khan N, Mohamad NA, Hameed MA, Ismail NE. Eating Habits and Body Weight Profiles Among Undergraduate Students in UiTM Puncak Alam , 2015;(Chuser 2011):274-80.

20. Stea TH, Torstveit MK. Association of lifestyle habits and academic achievement in Norwegian adolescents: a cross-sectional study. 2014;14(829):1-8.

21. Poobalan A, Aucott L. Obesity Among Young Adults in Developing Countries: A Systematic Overview. Curr Obes Rep 2016;5(1):2-13.

22. Ramaiah R. Prevalence of obesity and awareness of its risk factors among medical students of a rural teaching hospital of south India: a cross-sectional study. Int J Med Sci Public Heal 2015;4(10):1373.

23. WHO. Global health estimates 2015: deaths by cause, age, sex, by country and by region, 2000-2015. 2016.

24. Kumar C, Kiran K, Sagar V, Kumar M. Association of hypertension with obesity among adults in a rural population of Jharkhand. Int J Med Sci Public Heal 2016;5(12):2545.

25. Voges MM, Giabbiconi CM, Schöne B, Waldorf M, Hartmann AS, Vocks S. Gender differences in body evaluation: Do men show more self-serving double standards than women? Front Psychol 2019;10(MAR):1-12.

26. Wynn BD. The Impact of Media on Body Images of Young Women. Res Pap Pap 473 http//opensiuc.lib.siu.edu/gs_rp/473 2012;1-46.

27. Thielemann B. Assessment of nutritional knowledge and eating behaviors on the weight and obesity of college students A ss e ss $m$ e nt of Nutritional $K$ nowl e dg e and E ating B e havior s on th e W e ight and O b e s ity of Coll e g e Stud e nt s. Gen Hum Environ Sci Undergrad Honor Theses 3 http//scholarworks.uark.edu/ghesuht/3 2012;

28. Westerman D, Spence PR, Van Der Heide B. Social Media as Information Source: Recency of Updates and Credibility of Information. J Comput Commun 2014;19(2):171-83.

29. Li R, Suh A. Factors Influencing Information credibility on Social Media Platforms: Evidence from Facebook Pages. Procedia Comput Sci [Internet] 2015;72:314-28. Available from: http://dx.doi.org/10.1016/j.procs.2015.12.146

30. Hargrove EJ, Berryman DE, Yoder JM, Beverly EA. Assessment of Nutrition Knowledge and Attitudes in Preclinical Osteopathic Medical Students. J Am Osteopath Assoc 2017;117(10):622.

31. Arilewola Abosede Omotola. Knowledge and Attitude towards Obesity among Secondary School Students of Royal Crystal College , Ile-lfe, Nigeria Article by Arilewola Abosede Omotola Research questions Research objectives. Texila Int J Public Heal 2017;5(1):1-14.

32. Adeleke SA, Abioye-Kuteyi EA, Sikuade 00, Olusayo Al. Knowledge of Obesity among staff of the International Institute of Tropical Agriculture, Nigeria. Int J Curr Res Rev [Internet] 2015;7(22):22-8. Available from: 
https://www.researchgate.net/publication/286925132_Knowledge_of_Obesity_among_The_Staff_of_the_International_Institute_of_Tropical_Agriculture_N 33. World Health Organization. Fruit, vegetables and NCD prevention . 2003. Available from: http://www.who.int/dietphysicalactivity/media/en/gsfs_fv.pdf 34. Oluwakanyinsola Ojuolape Silva, Olayinka O. Ayankogbe TOO. Knowledge and consumption of fruits and vegetables among secondary school students of Obele Community Junior High School, Surulere, Lagos State, Nigeria. J Clin Sci 2017;14(2):68-73.

35. Layade A.A. Al. Fruit and Vegetable Consumption Among Students. RJOAS 2014;6(June):3-8.

36. Banwat ME, Lar LA, Daboer J, Audu S, Lassa S. Knowledge and intake of fruit and vegetables consumption among adults in an urban community in North Central Nigeria. Niger Heal J [Internet] 2012;12(1):12-15. Available from: http://www.ajol.info/index.php/nhj/article/view/81244

37. Poobalan AS, Aucott LS, Clarke A, Smith WCS. Diet behaviour among young people in transition to adulthood (18-25 year olds): a mixed method study. Heal Psychol Behav Med 2014;2(1):909-28.

38. Cutler DM, Glaeser EL, Shapiro JM. Why Have Americans Become More Obese? J Econ Perspect 2003;17(3):93-118.

39. Sabharwal M. Review Article Barriers in adopting a healthy lifestyle: Insight from college youth. Int J Med Sci Public Heal 2017;6(3):439-48.

\section{Tables}

Table 1: Socio-demographic Characteristics of Respondents

\begin{tabular}{|c|c|c|}
\hline Variable & Frequency $(n=394)$ & Percentage (\%) \\
\hline \multicolumn{3}{|l|}{ Age (yrs.) } \\
\hline$<20$ & 182 & 46.2 \\
\hline$>20$ & 212 & 53.8 \\
\hline Mean $\pm S D$ & $20.25 \pm 2.7$ & \\
\hline \multicolumn{3}{|l|}{ Sex } \\
\hline Female & 209 & 53.0 \\
\hline Male & 185 & 47.0 \\
\hline \multicolumn{3}{|l|}{ Ethnicity } \\
\hline Yoruba & 347 & 88.1 \\
\hline Others & 47 & 11.9 \\
\hline \multicolumn{3}{|l|}{ Religion } \\
\hline Christianity & 338 & 85.8 \\
\hline Islam & 56 & 14.2 \\
\hline \multicolumn{3}{|l|}{ Marital Status } \\
\hline Single & 381 & 96.7 \\
\hline Married & 13 & 3.3 \\
\hline \multicolumn{3}{|l|}{ Number of Siblings } \\
\hline $4 \&$ below & 284 & 72.1 \\
\hline $5 \&$ above & 110 & 27.9 \\
\hline \multicolumn{3}{|c|}{ Position in the Family } \\
\hline $1^{\text {st }}-3^{\text {rd }}$ & 290 & 73.6 \\
\hline $4^{\text {th }} \&$ above & 104 & 26.4 \\
\hline \multicolumn{3}{|c|}{ Father's Level of Education } \\
\hline No formal & 22 & 5.6 \\
\hline Primary & 24 & 6.1 \\
\hline Secondary & 65 & 16.5 \\
\hline Tertiary & 279 & 70.8 \\
\hline \multicolumn{3}{|c|}{ Mother's Level of Education } \\
\hline No formal & 24 & 6.1 \\
\hline Primary & 24 & 6.1 \\
\hline Secondary & 95 & 24.1 \\
\hline Tertiary & 247 & 62.7 \\
\hline \multicolumn{3}{|c|}{ Father's Occupation } \\
\hline Self employed & 187 & 47.5 \\
\hline Trader & 29 & 7.4 \\
\hline Retired & 45 & 11.4 \\
\hline Civil Servant & 131 & 33.7 \\
\hline \multicolumn{3}{|c|}{ Mother's Occupation } \\
\hline Self employed & 207 & 52.5 \\
\hline Trader & 23 & 5.8 \\
\hline Retired & 15 & 3.8 \\
\hline Civil Servant & 147 & 37.9 \\
\hline \multicolumn{3}{|l|}{ Current Level } \\
\hline 100 & 62 & 15.7 \\
\hline 200 & 196 & 49.7 \\
\hline 300 & 79 & 20.1 \\
\hline 400 & 57 & 14.5 \\
\hline \multicolumn{3}{|c|}{$\overline{\text { Monthly Stipends }(n=386)}$} \\
\hline & 354 & 91.7 \\
\hline 20,000 and Below & 32 & 8.3 \\
\hline Above 20,000 & & \\
\hline
\end{tabular}




\begin{tabular}{|c|c|c|}
\hline Obesity variable & Yes & No \\
\hline Heard of obesity $(n=394)$ & $373(94.7 \%)$ & $21(5.3 \%)$ \\
\hline$(n=185)$ & $170(91.9 \%)$ & $15(8.1 \%)$ \\
\hline$(n=209)$ & $203(97.1 \%)$ & $6(2.9 \%)$ \\
\hline Source of information ( $n=373$ ) & Frequency & Percentage \\
\hline Books & 157 & $42.1 \%$ \\
\hline Media & 205 & $55.0 \%$ \\
\hline Lectures & 99 & $26.5 \%$ \\
\hline Friends & 109 & $29.2 \%$ \\
\hline Health workers & 98 & $26.3 \%$ \\
\hline Internet & 104 & $27.9 \%$ \\
\hline General knowledge ( $n=373$ ) & Correct response & Incorrect response \\
\hline Obesity refers to being exc essively fat or overweight & $354(94.9 \%)$ & $19(5.1 \%)$ \\
\hline Obesity is linked to multiple factors & $105(28.2 \%)$ & $268(71.8 \%)$ \\
\hline Obesity is associated with serious health conditions & $28(7.5 \%)$ & $345(92.5 \%)$ \\
\hline Obesity is a chronic disease & $255(68.4 \%)$ & $118(31.6 \%)$ \\
\hline Obesity can affect all sexes & $185(49.5 \%)$ & $188(50.5 \%)$ \\
\hline Obesity is linked to sedentary lifestyles & $308(82.6 \%)$ & $65(17.4 \%)$ \\
\hline \multicolumn{3}{|l|}{ Obesity assessment } \\
\hline Heard of BMI & $128(34.3 \%)$ & $245(65.7 \%)$ \\
\hline Meaning of BMI $(n=128)$ & $108(84.4 \%)$ & $20(15.6 \%)$ \\
\hline Normal BMI range & $52(40.6 \%)$ & $76(59.4 \%)$ \\
\hline Checked BMI in the last 3months & $31(24.2 \%)$ & $97(75.8 \%)$ \\
\hline Grouping of obesity knowledge & Frequency & Percentage \\
\hline Good knowledge & 142 & $36.0 \%$ \\
\hline Poor knowledge & 252 & $64.0 \%$ \\
\hline Obesity knowledge by sex & Good knowledge & Poor knowledge \\
\hline Male & $49(34.5 \%)$ & $136(54.0 \%)$ \\
\hline Female & $93(65.5 \%)$ & $116(46.0 \%)$ \\
\hline
\end{tabular}

Table 3: Perception of obesity by the respondents

$N=373$

\begin{tabular}{|c|c|c|c|c|}
\hline Perception of obesity & SA & A & $\mathrm{D}$ & SD \\
\hline Obesity is a disease & $142(38.1 \%)$ & $129(34.6 \%)$ & $69(18.5 \%)$ & $33(8.8 \%)$ \\
\hline It can lead to stigmatization & $100(26.8 \%)$ & $168(45.1 \%)$ & 49 (13.1\%) & $56(15.0 \%)$ \\
\hline Obesity can be treated medically & $116(31.1 \%)$ & $203(54.4 \%)$ & $39(10.5 \%)$ & $15(4.0 \%)$ \\
\hline An obese individual should see a doctor & $168(45.0 \%)$ & $167(44.8 \%)$ & $21(5.6 \%)$ & $17(4.6 \%)$ \\
\hline Dietary modification can prevent it & $153(41.0 \%)$ & $172(46.1 \%)$ & $23(6.2 \%)$ & $25(6.7 \%)$ \\
\hline Reducing daily salt intake is good & $108(29.0 \%)$ & $205(55.0 \%)$ & $42(11.2 \%)$ & $18(4.8 \%)$ \\
\hline Eating junks between meals can lead to obesity & $110(29.5 \%)$ & $184(49.3 \%)$ & $62(16.6 \%)$ & $17(4.6 \%)$ \\
\hline Physical inactivity increases the chance of being obese & $139(37.3 \%)$ & $169(45.3 \%)$ & $42(11.3 \%)$ & $23(6.1 \%)$ \\
\hline Obesity is an evidence of good living & $15(4.0 \%)$ & $22(5.9 \%)$ & $110(29.5 \%)$ & $226(60.6 \%)$ \\
\hline Enhances appearance & $26(7.0 \%)$ & $45(12.1 \%)$ & $116(31.1 \%)$ & $186(49.8 \%)$ \\
\hline Confers respect & $17(4.6 \%)$ & $32(8.6 \%)$ & $127(34.0 \%)$ & $197(52.8 \%)$ \\
\hline Measure socioeconomic status & $19(5.1 \%)$ & $45(12.1 \%)$ & $142(38.1 \%)$ & $167(44.7 \%)$ \\
\hline It makes one look mature & $18(4.8 \%)$ & $69(18.5 \%)$ & $109(29.2 \%)$ & $177(47.5 \%)$ \\
\hline It makes one attractive & $11(2.9 \%)$ & $18(4.8 \%)$ & $141(37.8 \%)$ & $203(54.5 \%)$ \\
\hline It makes clothes to fit better & $16(4.3 \%)$ & $27(7.2 \%)$ & $123(33.0 \%)$ & 207 (55.5\%) \\
\hline A fat student is wealthier than a slim student. & $22(5.6 \%)$ & $37(9.4 \%)$ & $113(28.7 \%)$ & $222(56.3 \%)$ \\
\hline Grouping of Perception & \multicolumn{2}{|c|}{ Frequency } & \multicolumn{2}{|c|}{ Percentage } \\
\hline Positive perception & \multicolumn{2}{|c|}{218} & \multicolumn{2}{|c|}{58.4} \\
\hline Negative perception & \multicolumn{2}{|c|}{155} & \multicolumn{2}{|c|}{41.6} \\
\hline Perception of obesity by sex & \multicolumn{2}{|c|}{ Positive Perception n (\%) } & \multicolumn{2}{|c|}{ Negative perception n (\%) } \\
\hline Male & \multicolumn{2}{|c|}{$92(42.2 \%)$} & \multicolumn{2}{|c|}{$78(50.3 \%)$} \\
\hline Female & \multicolumn{2}{|c|}{$126(57.8 \%)$} & \multicolumn{2}{|c|}{$77(49.7 \%)$} \\
\hline
\end{tabular}

SA-Strongly Agree, A-Agree, D-Disagree, SD-Strongly Disagree 
Table 4: Dietary behaviour of the respondents

\begin{tabular}{|c|c|c|c|}
\hline Variables & Male n (\%) & Female n (\%) & Total \\
\hline \multicolumn{4}{|l|}{ Fruit } \\
\hline$<$ Once/week & $71(42.0 \%)$ & $98(58.0 \%)$ & $169(45.3 \%)$ \\
\hline 1-2 times/week & $55(49.5 \%)$ & $56(50.5 \%)$ & $111(29.8 \%)$ \\
\hline 3-4 times/week & 27 (52.9\%) & $24(47.1 \%)$ & $51(13.7 \%)$ \\
\hline 5-6times/week & $7(58.3 \%)$ & $5(41.7 \%)$ & $12(3.2 \%)$ \\
\hline Everyday & $10(33.3 \%)$ & $20(66.7 \%)$ & $30(8.0 \%)$ \\
\hline \multicolumn{4}{|l|}{ Vegetable } \\
\hline$<$ Once/week & $69(44.2 \%)$ & $87(55.8 \%)$ & $156(41.8 \%)$ \\
\hline 1-2 times/week & $44(41.7 \%)$ & $67(58.3 \%)$ & $115(30.8 \%)$ \\
\hline 3-4 times/week & $39(57.4 \%)$ & $29(42.6 \%)$ & $68(18.2 \%)$ \\
\hline 5-6times/week & $7(36.8 \%)$ & $12(63.2 \%)$ & $19(5.1 \%)$ \\
\hline Everyday & $7(46.7 \%)$ & $8(53.3 \%)$ & $15(4.1 \%)$ \\
\hline \multicolumn{4}{|l|}{ Fried foods } \\
\hline$<$ Once/week & $43(41.7 \%)$ & $60(58.3 \%)$ & $103(27.3 \%)$ \\
\hline 1-2 times/week & $41(42.7 \%)$ & $55(57.3 \%)$ & $96(25.7 \%)$ \\
\hline 3-4 times/week & $50(52.3 \%)$ & $46(47.7 \%)$ & $96(25.7 \%)$ \\
\hline 5-6times/week & $16(43.2 \%)$ & $21(56.8 \%)$ & $37(10.3 \%)$ \\
\hline Everyday & $20(48.8 \%)$ & $21(51.2 \%)$ & $41(11.0 \%)$ \\
\hline \multicolumn{4}{|l|}{ Snacks } \\
\hline$<$ Once/week & $39(49.4 \%)$ & $40(50.6 \%)$ & $79(20.2 \%)$ \\
\hline 1-2 times/week & $32(40.0 \%)$ & $48(60.0 \%)$ & $80(21.4 \%)$ \\
\hline 3-4 times/week & $35(44.9 \%)$ & $43(55.1 \%)$ & $78(20.9 \%)$ \\
\hline 5-6times/week & $26(44.8 \%)$ & $32(55.2 \%)$ & $58(15.6 \%)$ \\
\hline Everyday & $38(48.7 \%)$ & $40(51.3 \%)$ & $78(20.9 \%)$ \\
\hline \multicolumn{4}{|l|}{ Sweets (candies) } \\
\hline$<$ Once/week & $75(49.0 \%)$ & $78(51.0 \%)$ & $153(41.0 \%)$ \\
\hline 1-2 times/week & $39(41.9 \%)$ & $54(58.1 \%)$ & $93(24.9 \%)$ \\
\hline 3-4 times/week & $19(50.0 \%)$ & $19(50.0 \%)$ & $38(10.2 \%)$ \\
\hline 5-6times/week & $8(28.6 \%)$ & $20(71.4 \%)$ & $28(7.5 \%)$ \\
\hline Everyday & $29(47.5 \%)$ & $32(52.5 \%)$ & $61(16.4 \%)$ \\
\hline \multicolumn{4}{|l|}{ Soft drink } \\
\hline$<$ Once/week & $43(36.4 \%)$ & $75(63.6 \%)$ & $118(31.6 \%)$ \\
\hline 1-2 times/week & $52(45.6 \%)$ & $62(54.4 \%)$ & $114(30.6 \%)$ \\
\hline 3-4 times/week & $32(48.5 \%)$ & $34(51.5 \%)$ & $66(17.7 \%)$ \\
\hline 5-6times/week & $11(47.8 \%)$ & $12(52.2 .0 \%)$ & $23(6.2 \%)$ \\
\hline Everyday & $32(61.5 \%)$ & $20(38.5 \%)$ & $52(13.9 \%)$ \\
\hline \multicolumn{4}{|l|}{ Barbecue (suya) } \\
\hline$<$ Once/week & $83(44.1 \%)$ & $105(55.9 \%)$ & $188(50.4 \%)$ \\
\hline 1-2 times/week & $31(43.1 \%)$ & $41(56.9 \%)$ & $72(19.3 \%)$ \\
\hline 3-4 times/week & $18(54.5 \%)$ & $15(45.5 \%)$ & $33(8.8 \%)$ \\
\hline 5-6times/week & $7(41.2 \%)$ & $10(58.8 \%)$ & $17(4.6 \%)$ \\
\hline Everyday & $31(49.2 \%)$ & $32(50.8 \%)$ & $63(16.9 \%)$ \\
\hline \multicolumn{4}{|l|}{ Grouping of DB } \\
\hline Good DB & $70(41.2 \%)$ & $88(43.3 \%)$ & $158(42.4 \%)$ \\
\hline Poor DB & $100(58.8 \%)$ & 115 (56.7\%) & $215(57.6 \%)$ \\
\hline
\end{tabular}

DB; Dietary Behaviour

Table 5: Relationship between obesity knowledge, perception and dietary behaviour of respondents

\begin{tabular}{|c|c|c|c|c|c|}
\hline \multirow[t]{2}{*}{ Variables } & & \multicolumn{2}{|c|}{ Perception } & \multirow[t]{2}{*}{$\mathrm{x}^{2}$} & \multirow[t]{2}{*}{ P-value } \\
\hline & & Negative & Positive & & \\
\hline \multirow[t]{4}{*}{ Obesity Knowledge } & Poor & $111(48.1 \%)$ & 120 (51.9\%) & 10.546 & 0.001 \\
\hline & Good & $44(31.0 \%)$ & 98 (69.0\%) & & \\
\hline & & \multicolumn{2}{|c|}{ Dietary Behaviour } & & \\
\hline & & Poor & Good & & \\
\hline Obesity & Poor & 137 (59.3\%) & 94 (40.7\%) & 0.690 & 0.450 \\
\hline Knowledge & Good & $78(54.9 \%)$ & 64 (45.1\%) & & \\
\hline
\end{tabular}

